\title{
Jacques Beaudry, Hubert Aquin: la course contre la vie
}

\section{Simona Rossi}

\section{(2) OpenEdition}

\section{Journals}

\section{Edizione digitale}

URL: http://journals.openedition.org/studifrancesi/9366

DOI: 10.4000/studifrancesi.9366

ISSN: 2427-5856

\section{Editore}

Rosenberg \& Sellier

\section{Edizione cartacea}

Data di pubblicazione: 1 juin 2008

Paginazione: 233

ISSN: 0039-2944

\section{Notizia bibliografica digitale}

Simona Rossi, «Jacques Beaudry, Hubert Aquin: la course contre la vie», Studi Francesi [Online], 154 (LII I

I) | 2008, online dal 30 novembre 2015, consultato il 09 janvier 2021. URL: http://

journals.openedition.org/studifrancesi/9366 ; DOI: https://doi.org/10.4000/studifrancesi.9366

\section{Questo documento è stato generato automaticamente il 9 janvier 2021}

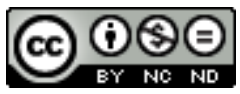

Studi Francesi è distribuita con Licenza Creative Commons Attribuzione - Non commerciale - Non opere derivate 4.0 Internazionale. 


\section{Jacques Beaudry, Hubert Aquin: la course contre la vie}

Simona Rossi 


\section{NOTIZIA}

JACQUES BEAUDRY, Hubert Aquin: la course contre la vie, Montréal, Hurtubise, 2006, pp. 119.

In questo testo toccante sullo scrittore Hubert Aquin, il saggista Jacques Beaudry pone una domanda a cui è difficile dare una risposta: le opere di scrittori morti suicidi possono aiutare l'uomo moderno a meglio comprendere alcune delle sfaccettature del mondo in cui loro stessi non hanno sopportato di vivere a lungo?

Dopo essersi dedicato lungamente a Cesare Pavese, Beaudry si sofferma qui sullo scrittore Hubert Aquin (1929-1977), morto suicida. La sua attenta analisi offre ai lettori affascinanti scorci dell'esistenza e della scrittura di un uomo che è stato animato fino alla fine da una sorta di sforzo sovrumano per trasformare il destino in libertà. Non ce l'ha fatta, non è riuscito a conciliare il suo essere irrequieto e insofferente di fronte ad ogni limite con l'immobilità, l'incoerenza, l'indecisione della società nella quale viveva. Ha lottato fino allo stremo, però, e in ognuno dei suoi scritti traspaiono i contorni accesi della sua passione e del suo impegno per dare un'impronta diversa alla cultura del Québec, per liberarla dai suoi lacci e per infonderle un nuovo, ardente respiro. Beaudry fa rivivere con maestria la sete di cambiamento di Aquin, lascia parlare i suoi testi, ne svela i dettagli più segreti, non censura i suoi sogni, i suoi miti, le sue umane debolezze, le sue grida. Come fa notare il critico, l'ultimo grido di Hubert Aquin sarà il suo suicidio, avvenuto il 15 marzo del 1977. Il lavoro di Beaudry è una solida e commossa monografia, che non porta certezze o risposte risolutive ai numerosi quesiti posti, ma che, nei tre capitoli che la compongono («La guerre totale»; «Le roman total»; «L'homme total»), riesce a tratteggiare un intenso e accurato ritratto dello scrittore, un meritato omaggio a trent'anni dalla sua scomparsa. Il lavoro è dotato di un'utile sezione dedicata alle «Sources», in cui il lettore trova tutti i riferimenti bibliografici. 